San Jose State University

SJSU ScholarWorks

Master's Theses

Master's Theses and Graduate Research

Summer 2017

\title{
A Qualitative Analysis of a Team's Experience of Coping with Bereavement After the Death of a Head Coach
}

Matthew Paul Gonzalez

San Jose State University

Follow this and additional works at: https://scholarworks.sjsu.edu/etd_theses

\section{Recommended Citation}

Gonzalez, Matthew Paul, "A Qualitative Analysis of a Team's Experience of Coping with Bereavement After the Death of a Head Coach" (2017). Master's Theses. 4846.

DOI: https://doi.org/10.31979/etd.j7zp-96z4

https://scholarworks.sjsu.edu/etd_theses/4846

This Thesis is brought to you for free and open access by the Master's Theses and Graduate Research at SJSU ScholarWorks. It has been accepted for inclusion in Master's Theses by an authorized administrator of SJSU ScholarWorks. For more information, please contact scholarworks@sjsu.edu. 


\title{
A QUALITATIVE ANALYSIS OF A TEAM'S EXPERIENCE OF COPING WITH BEREAVEMENT AFTER THE DEATH OF A HEAD COACH
}

\author{
A Thesis \\ Presented to \\ The Faculty of the Department of Kinesiology \\ San José State University \\ In Partial Fulfillment \\ of the Requirements for the Degree \\ Master of Arts
}

by

Matthew Gonzalez

August 2017 
(C) 2017

Matthew Gonzalez

ALL RIGHTS RESERVED 
The Designated Thesis Committee Approved the Thesis Titled

A QUALITATIVE ANALYSIS OF A TEAM'S EXPERIENCE OF COPING WITH BEREAVEMENT AFTER THE DEATH OF A HEAD COACH

by

Matthew Gonzalez

APPROVED FOR THE DEPARTMENT OF KINESIOLOGY

SAN JOSÉ STATE UNIVERSITY

August 2017

Tamar Semerjian, Ph.D. Department of Kinesiology

Ted M. Butryn, Ph.D Department of Kinesiology

Matthew Masucci, Ph.D Department of Kinesiology 


\title{
ABSTRACT \\ A QUALITATIVE ANALYSIS OF A TEAM'S EXPERIENCE OF COPING WITH BEREAVEMENT AFTER THE DEATH OF A HEAD COACH
}

\author{
by Matthew Gonzalez
}

The consequences of coping with death as an athlete have been documented in the literature by a variety of studies. However, these studies have remained largely focused on coping with the death of a teammate. This study examined the inter- and intrapersonal impact of experiencing the death of a head coach. Experiencing the death of a head coach during the season may have profound and varied psychosocial consequences for all members of a team. A collegiate team was identified as having experienced the death of its head coach during his tenure and from that team five participants (four players and one assistant coach) shared their stories during semi-structured interviews which were thematically analyzed. Major emergent themes from the interviews suggested that: members of the team experience bereavement differently which may have interpersonal consequences during a shared tragedy; memorials and tributes play a significant role in the process of individual and collective bereavement; and members of the team will make an effort to continue the presence of the deceased individual as well as perpetuate their memory in various ways. These results add breadth to the slowly growing literature that documents the effect that a death has on athletes. These findings and the findings of other similar studies have significant implications for informing the holistic design of service provision of athletes by applied sport psychology or mental health professionals. 


\section{ACKNOWLEDGEMENTS}

It is unlikely that I would have been able to complete this process without the help of several individuals. First and foremost, all the members of my committee provided me with far more support than I could have ever asked or hoped for. A very special thanks to both Dr. Butryn for ingraining enough confidence in me to get this whole project started and to Dr. Semerjian for her persistence in getting me through the finish line. Dr. Masucci, thank you so much for lending your insight to this project and for your extended support as I worked my way through the Kinesiology program.

To my mother and father, it is unlikely that I ever decided to pursue a graduate education in Kinesiology without you both. And once I started down this path, you both provided unwavering love and support and pushed me to the end. I love you both so much and I could never adequately express how thankful I am that you have both given me everything that you could so that I may pursue this extraordinary gift of education.

To my wife, there isn't a moment going through this program where you weren't standing by my side, ready to help me. You are the best friend, partner, and competitive classmate that I could have ever imagined. There are not enough words to accurately express how grateful I am that you are in my life.

Finally, my sincerest appreciation goes out to the participants of this study. By willingly taking the time to share your heartfelt stories, you have quite literally made this entire thesis possible. For the gift of your time and experiences, I am forever grateful. 


\section{TABLE OF CONTENTS}

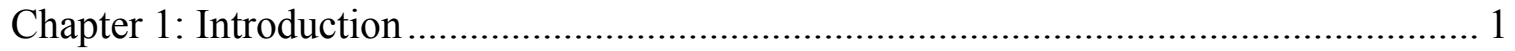

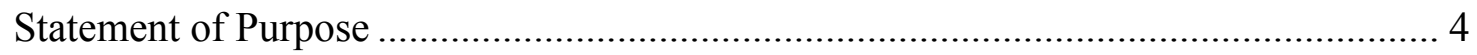

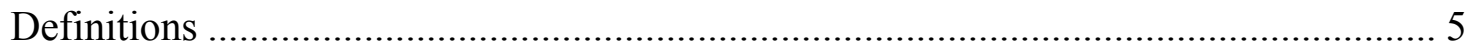

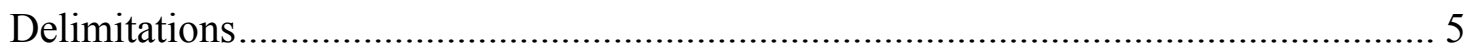

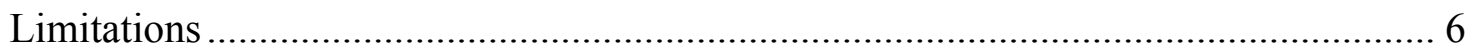

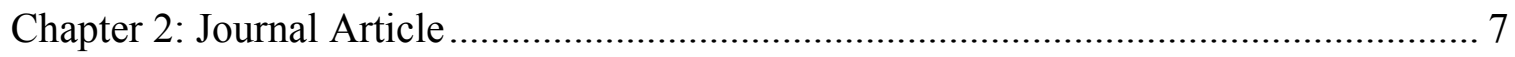

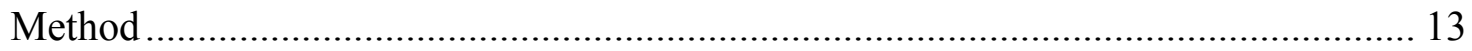

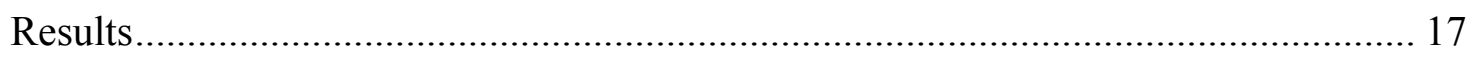

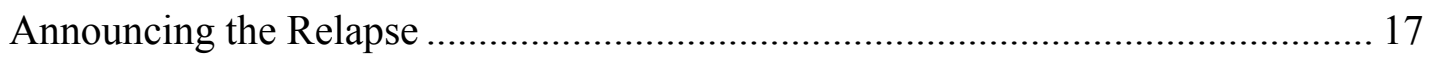

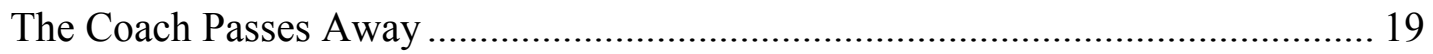

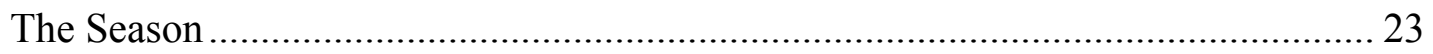

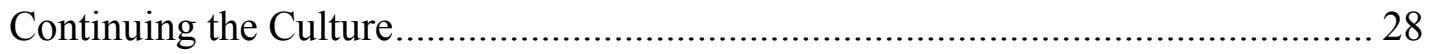

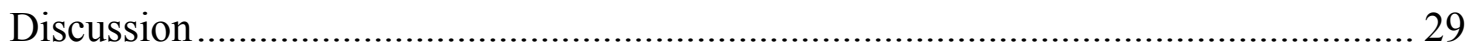

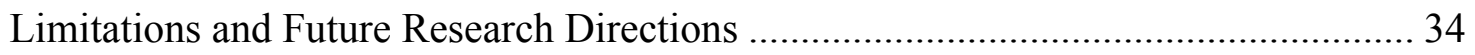

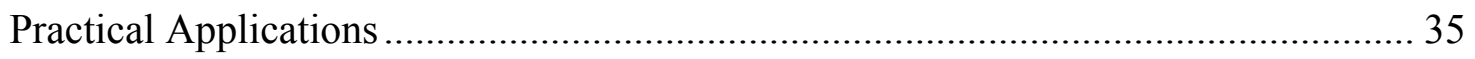

Chapter 3: Extended Review of Literature ………………........................................ 38

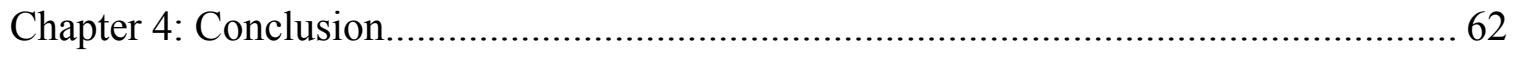

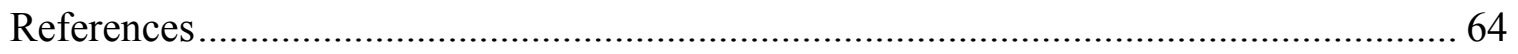




\section{CHAPTER 1: INTRODUCTION}

Death in sport is an extremely rare event. According to an annual report published by the National Center for Catastrophic Sport Injury Research (NCCSIR), only 31 high school and college athletes died from sport participation during 2013 (National Center for Catastrophic Sport Injury Research, 2014). Of those 31 athletes, only nine died from incidents directly related to the sport, with the remaining 22 athletes dying from indirect causes, usually related to a previously undiagnosed or mismanaged health condition. Calculating these cases across the nation of the many millions of high school and collegiate athletes who play every year, this makes up a statistical likelihood of death in sport so miniscule that the risk is virtually nil.

Despite the mathematical unlikelihood of ever experiencing this type of sporting tragedy, these events definitely warrant academic attention due to the potential for an adverse emotional response. Athletes are not immune to bereavement and will have a visceral response to the death of a competitor or teammates similar to the response any other person would have to the death of a significant member of their social circle (Henschen \& Heil, 1992). Some studies have found that the response to the death of a competitor or teammate may manifest itself differently than a normal loss response (Andersson, 2010; Vernacchia et al., 1997). There is also a possibility for the experience to be traumatic enough to cause withdrawal from the sport (Kerr, 2007). In this instance, the potential effect can be twice as devastating, as now the person must grieve over the loss of a close relationship as well as the symbolic death of his or her sporting identity. 
The limited research that analyzes the experience of death in sport has done so entirely within the context of analyzing the experience of losing a teammate. A sport organization has many more members than just the players; important members can include coaches, training staff, as well key organizational figures such as a general manager. It is the purpose of this study to investigate the experience of losing a coach.

To date, there have been no published studies analyzing this specific event. That is not to say that this is an occurrence that has not been documented. The death of Minnesota Timberwolves head coach, Flip Saunders, recently garnered extensive media attention after he passed away from lymphoma less than a week before the start of the 2015-2016 season. However, outside of analyzing the social media response of the players, there is no way to tell if there were any significant psychological effects of Coach Saunders' death on the players. In addition to that, there was a brief article published in Lacrosse Magazine in October 2015 that detailed the experiences of a team whose coach also passed away from cancer (Logue, 2015).

Predicting the psychological outcomes of such a tragic event may prove difficult. This is because when a person dies, he or she does not leave a single hole in a single social system. Instead, the deceased individual leaves multiple holes in every social system of which he or she was a member (Vernon, 1970). This could prove to be problematic when analyzing the grief response of a player to the death of a coach because a coach has multiple major relationships with his or her athletes that culminate under the umbrella term "coach." Experiencing the death of a coach means that the athlete may lose 
more than just a coach; he or she could also be losing a friend, a teacher, and/or a parent surrogate (Ainsworth, 1989).

It is possible then, that a modulating variable of the athlete's experience of bereavement may be the athlete's attachment relationship with the coach. Ainsworth (1989) briefly suggested in one of her papers on adult attachments that a coach could feasibly play the role of a parent surrogate in the instance of a secure attachment. Davis and Jowett $(2010,2014)$ found evidence supporting the claim that secure attachments could be formed between athletes and coaches. Since secure attachment relationships are very close emotional relationship and close relationships produce stronger experiences of grief (Wayment \& Vierthaler, 2002), it can be reasonably hypothesized that the experience of losing one's head coach has the potential to be a very emotional experience.

The experience of bereavement is not a straightforward process. There are myriad personal and social variables that must be accounted for and considered. Due to these inherent complexities, the academic understanding of coping with bereavement has changed significantly since Freud's writings about this experience (1917). Kübler-Ross' (1969) stages of grief model is perhaps the most recognizable perspective of the experience of bereavement. But for several reasons, the model has been critiqued (Marcu, 2007; Strobe, Schut, \& Boerner, 2017) for a variety of reasons. One of these critiques has been the lack of attention paid to the impact society has on an individual's grieving process. Within the scope of a highly social atmosphere, such as that presented in a sports team, the modulation of the bereavement experience by a social system needs to be 
adequately accounted for. Jakoby's (2012) cognitive-structural model of grief directly accounts for the impact of a social system by integrating framing rules, feeling rules, display rules, and social resources into an individual's process of coping.

In addition, because a team by definition is a collective of people representing and functioning as a single entity, this could mean that the team is also grieving collectively. However, collectives may not technically grieve at all. Instead, it has been contended that a group of individuals grieve within the context of the group (Gilbert, 1996). Semantics aside, it is evident that groups do make decisions in response to a shared loss. Zinner (1985) has labeled these actions "rights and obligations" in her model of group survivorship. According to Zinner, how these rights and obligations are attended to will help predict the coping process of the group.

The tragic, yet compelling, nature of investigating the loss of a coach is that each person will grieve as an individual while at the same time being influenced by the person's dominant social structure, the team, which is also grieving. The incredibly nuanced nature of the interaction of these intense emotions is made even more complex as the grieving athletes must persist towards high performance in the face of bereavement. This can lead to an extremely emotionally charged atmosphere which is not conducive to exceptional sport performance (Vernacchia et al. 1997).

\section{Statement of Purpose}

The purpose of this study was to qualitatively analyze the bereavement experience of a team after the death of its head coach during his tenure. Four athletes and one assistant coach were interviewed about their experience of bereavement after living through the 
death of the team's head coach, Coach Tom. The interviews were thematically analyzed and the results contextualized within the frameworks of the Jakoby's cognitive-structural model of grief (2012) and Zinner's (1985) model of group survivorship.

\section{Definitions}

1. Grief is defined as "the anguish experienced after significant loss, usually the death of a beloved person" (VandenBos, 2015, p. 470)

2. Bereavement is defined as "the condition of having lost a loved one to death" (VandenBos, 2015, p. 120). The distinction between "grief" and bereavement is small, yet critical, especially in regards to athletes and loss. Grief is the response to losing something whereas bereavement is the response to losing someone. In other words, all bereavement experiences are grief experiences; but not all grief experiences are bereavement experiences. Astle (1986) lists several types of loss experiences that an athlete may face is having damage done to one's athletic identity. The emotional response to this "loss" is grief, not bereavement, thus elucidating the necessity of using the proper terminology.

\section{Delimitations}

This study was delimited to the following participants:

1. Players from the women's water polo team who had previously played for Coach Tom and played during the 2014 season.

2. Players from the women's water polo team who had not previously played for Coach Tom, but played during the 2014 season.

3. Coaches who participated in the 2014 season. 


\section{Limitations}

1. The data was collected and analyzed a significant amount of time after the death of the head coach, roughly two years after the loss. This means there has been an extensive amount of time for the athlete or key stakeholder to emotionally process the death. Bereavement is an idiosyncratic experience (Gilbert, 1996; KüblerRoss \& Kessler, 2005) that changes over time. Results may be different than if interviews with the same participants were conducted two weeks or two months after the death instead of two years.

2. Snowball sampling was used to identify participants throughout the study. Although this has been determined to be an effective method of recruitment (Amis, 2005), there is a risk that the results of the study may only reflect similar opinions from people who are emotionally close to each other. 


\title{
A Qualitative Analysis of a Team's Experience of Coping with Bereavement After the Death of a Head Coach
}

\author{
Matthew Gonzalez, Tamar Semerjian, Ted Butryn, Matthew Masucci \\ San José State University
}

The consequences of coping with death as an athlete have been documented in the literature by a variety of studies. However, these studies have remained largely focused on coping with the death of a teammate. This study examined the inter- and intrapersonal impact of experiencing the death of a head coach. Experiencing the death of a head coach during the season may have profound and varied psychosocial consequences for all members of a team. A collegiate team was identified as having experienced the death of its head coach during his tenure and from that team five participants (four players and one assistant coach) shared their stories during semi-structured interviews which were thematically analyzed. Major emergent themes from the interviews suggested that: members of the team experience bereavement differently which may have interpersonal consequences during a shared tragedy; memorials and tributes play a significant role in the process of individual and collective bereavement; and members of the team will make an effort to continue the presence of the deceased individual as well as perpetuate their memory in various ways. These results add breadth to the slowly growing literature that documents the effect that a death has on athletes. These findings and the findings of other similar studies have significant implications for informing the holistic design of service provision of athletes by applied sport psychology or mental health professionals.

Keywords: death, bereavement, grief, coach, coping, memorials

Statistically, a death in sport is a rare event. It is difficult to place an accurate estimate on the number of athletes who pass away from sport participation due to the lack of a central governing body which could record these numbers, as well as the lack of quality oversight in youth and community leagues. Despite the difficulty in accurately measuring the frequency of athlete deaths, the National Center for Catastrophic Sport Injury 
Research (NCCSIR), recorded that only 31 high school and college athletes died from sport participation during 2013 (National Center for Catastrophic Sport Injury Research, 2014).

The limited attention that this has received in the research may be partially explained by the fortunately sparse nature of these types of events. However, the potential magnitude with which one responds psychologically and physiologically to bereavement may be so intense (Raphael, 1994) that the experience of athlete bereavement deserves quality inspection in order to help inform the applied practice of mental health and sport psychology professionals in the event of its occurrence.

The limited research that investigates death in sport has focused wholly on the passing of an athlete in a variety of circumstances. Scholars have examined the death of an athlete due to a projectile injury sustained during a game (Karofsky, 1990); the death of an athlete due to an exercise related or previously undisclosed medical condition (Andersson, 2010; Henschen \& Heil, 1992; Vernacchia, Reardon, \& Templin, 1997); an athlete's suicide (Buchko, 2005), and deaths in sport which occurred from competing in a risk-taking sport (Doka, Schwarz, \& Schwarz, 1990; Kerr, 2007). However, the myopic focus on investigating the death of a teammate has limited the range what is understood about the experience of athlete bereavement.

Grief is defined as "the anguish experienced after significant loss, usually the death of a beloved person" (VandenBos, 2015, p. 470). Although grief is commonly conflated with the word bereavement, the two have slightly different meanings. Bereavement is defined as "the condition of having lost a loved one to death" (VandenBos, 2015, p. 120). 
Both instances deal with loss, but the mediating factor is whether or not the loss was a person. Astle (1986) defined different types of loss an athlete might be faced with. One type of loss could be the death of a teammate; this experience would be considered bereavement. Another type of loss could be that of an object, such as a lucky talisman; this experience of loss would be considered grief but not bereavement.

The study of bereavement has been developed mainly within the context of the bereaved individual's process of coping with the death. There is a significant body of research dedicated to understanding coping as it pertains to general life stressors, most notably the work done by Lazarus and Folkman (Folkman, 1984; Lazurus, 1993; Lazurus \& Folkman, 1984). Their work primarily, although not entirely, contends that an individual's ability to cope with a stressor presented by life is mediated by one's appraisal of the situation as well as one's perceived resources that one has available to cope with the situation. This theoretical view of coping (also known as the Transactional Model of Stress and Coping) with a life stressor could be extended to coping with death. However, when it comes to the study of bereavement, the application of these stress/coping theoretical orientations have been criticized heavily for a variety of reasons. This includes the inherent problems associated with framing bereavement as a threat rather than a normal, healthy event (Payne, Horn, \& Reif, 1999). It is likely that due to these extensive criticisms, that specialized theories explaining coping with death have been developed and have been more widely deployed in the research.

The manner in which scholars have framed bereavement has changed drastically since its research origins when Freud first formally investigated it in his published work 
Mourning and Melancholia (1917). His position on the nature of bereavement stated that one should progress through one's experience of bereavement by completing "grief work" with the ultimate goal of helping completely sever the bereaved individual from his or her emotional bonds with the deceased loved one. This concept of complete disengagement from the memories of a deceased love one has been has been almost wholly rejected by professionals. In fact, redefining the relationship through a continued bond is now considered to be a healthy, normal part of the coping process (Root \& Exline, 2014).

Perhaps the most recognizable work with regards to bereavement are the stages of grief which were first described in Kübler-Ross' seminal work: On Death and Dying (1969). The stages of grief define a series of psychological steps that a dying individual will pass through as he or she copes with the prospect of his or her death. These steps are: denial, anger, bargaining, depression, and acceptance. Although Kübler-Ross initially developed these by utilizing the experiences of terminally-ill patients who were coping with their own mortality, she found that the same phases applied to the family members of the terminally-ill patients as well. Although it was first developed nearly a half century ago, the stages of grief are still frequently utilized today to inform both practice and research (Strobe, Schut, \& Boerner, 2017).

Despite the widespread application of the stages of grief, Kübler-Ross' (1969) work has not gone without criticism. Often this criticism has been directed at the model's implied linearity (Marcu, 2007). It can be interpreted that the stages of grief imply that there is a singular path which one must travel in order to fully cope with grief. Kübler- 
Ross has since defended these steps against this criticism, contending that this implication was not an intention of the model (Kübler-Ross \& Kessler, 2005). There have been additional criticisms of the stages of grief, perhaps none quite as scathing as that put forth by Marcu who cites a “... lack of trans-cultural validity, omission of the social aspects of adjustment, and stages and tasks being prescriptive for experiencing dying or loss" (Marcu, 2007, p. 398). Her critique is not limited to Kübler-Ross' stages of grief, but implicates other earlier bereavement models which also imply linearity.

The dynamic nature of bereavement has been well documented by a variety of professionals. It has been established that coping with death is a process that may be progressive at times and regressive at others (Raphael, 1994). Additionally, the bereaved individual is likely not putting in continuous, linear effort towards healthy coping. This contention is best described by the Dual Process Model of Coping with Bereavement (Strobe \& Schut, 1999). Strobe and Schut contend that a bereaved individual "oscillates" between engaging in loss-oriented coping and restoration-oriented coping during the process of coping with the death of his or her loved one. Loss-oriented coping refers to actions taken that directly deal with the individual's experience of bereavement. Restoration-oriented coping, on the other hand, encompasses the bereaved individual's management of the "secondary" losses one experiences from losing a loved one such as learning how to do a new chore since the chore had previously been completed by the now deceased.

Although many of these theories allude to the mediating effect of social interaction on one's coping process, these theories generally do not explicitly analyze the effect of a 
social system on an individual's process of bereavement. In a highly impactful and meaningful social atmosphere such as that of a team, the importance of the teammates and coaches cannot be discounted as a potential variable to moderate the experience of bereavement. Jakoby's (2012) cognitive-structural model of grief may be promising to rectify this particular omission specifically with regards to the context of a socially influential collective such as a team. Jakoby utilized fundamentals derived from symbolic interactionism, structural functionalism, and behavior theory to develop a psychosocial theory which could appropriately account for a social system's effect on an individual's experience of bereavement. This model outlines a variety of social variables which may mediate one's bereavement experience such as: framing rules, feeling rules, display rules, and social/personal resources.

It is possible that the experience of losing another key member of the team, such as a head coach, may be differentiated from the experience of losing a teammate. But since there is no research that has formally explored the effect of experiencing the death of one's head coach, this cannot be definitively stated. It is worth noting that it has been suggested that players can develop a secure attachment relationship with their coaches (Ainsworth, 1989), a claim substantiated by the results of a study by Davis and Jowett (2010). Since close relationships produce more intense grief experiences (Wayment \& Vierthaler, 2002) this particular experience of athlete bereavement could be emotionally devastating. This represents an important gap in the research that should be investigated not just to inform future studies, but to help inform the practical strategy of a mental health or sport psychology professionals should they encounter this situation. Therefore, 
the purpose of this study was to qualitatively analyze the bereavement experience of a team after the death of its head coach during his tenure.

\section{Method}

Grief responses are individualized from person to person, even when the loss experience is the same (Gilbert, 1996). Therefore, to appropriately recognize these differences, it is imperative to choose a methodology which allows those differences to be fully displayed. It is in the spirit of these differences that a qualitative approach was chosen to explore this circumstance because central to the nature of qualitative research is the ontological assumption that there is no one singular reality that can be described (Creswell, 2007).

It was determined that to properly investigate this experience, one-on-one contact with the players who had experienced the death of their head coach would be required. A population was identified and after approval of the university's Institutional Review Board to carry out the investigation. Access to this population was gained by way of a gatekeeper. Gatekeepers have long played an integral part in helping researchers gain access to a population with which they have no meaningful rapport (Creswell, 2003). The gatekeeper was tasked with disseminating a recruitment email message to teammates and coaches who played the season following the coach's death. This message contained an abstract of the study as well as contact information should a participant decide to be interviewed. In addition to the recruitment message, participants were also recruited into the study by means of snowball sampling, which has also been determined to be an acceptable recruitment strategy (Amis, 2005). Five participants who were involved with 
the team during the season following the coach's death were recruited for the study in total, including four players and one assistant coach. While the number of participants was relatively small, this number represents as many participants who felt comfortable enough to discuss this emotionally charged topic out of an already small pool of participants that a single roster could provide. Also, the recruiting strategy from this study was intentionally non-aggressive out of respect for the bereaved athletes.

This study utilized interviews as they have been considered, "the most logical way to access realties" (Amis, 2005, p. 107). Specifically, the data collection instrument was a semi-structured or standardized open-ended interview (Amis, 2005) and was chosen for its mix of systematic inquiry, yet academic flexibility in data collection (Berg, 2004). Since there is no previous research documenting bereavement experiences in the context of losing one's head coach, the data collection instrument was designed such that the main questions were broad questions that prompted the participants to tell a chronological story of their bereavement experience. Most of these questions were two-fold. Specifically, they first asked the participants to describe their own personal experiences and then asked the participants to reflect and describe their perceived experiences of their teammates. In addition, icebreaker questions were designed with the intention of developing rapport with the participants, something that was especially important given the emotional nature of the study (Berg, 2004).

The interviews were transcribed verbatim with the exception of removing all sources of identifying information. In order to maintain participant confidentiality, all participants selected their own pseudonym before the commencement of the interview. A thematic 
analysis was conducted to analyze the content of the interviews. The interviews were analyzed inductively utilizing a systematic coding strategy (Creswell, 2016) whereby the transcript is broken down into pieces of texts which are developed into codes and then finally refined down into central themes with the ultimate goal of identifying experiences common to all or most of the participants. These codes and themes were generated without the support of specialized qualitative analysis software, as qualitative data can be effectively analyzed manually or digitally (Gratton \& Jones, 2004). In order to assist with organization as well as provide additional context to the themes that were derived from the interviews, the following results are presented chronologically. Also, although the interviews were transcribed verbatim, the quotes presented below have been edited for the sake of clarity, such that vocalized pauses and half-spoken words have been removed.

Although qualitative research is not outright concerned with achieving a specified mark of validity, it is important to design and implement a quality study. There is no standardized list of criteria that qualitative researchers unanimously agree upon, as this debate has been contested since Lincoln and Guba's (1985) formative work on this topic. The study primarily utilized two commonly rigorous practices in carrying out this research. First, care was taken to be introspective through the entire research process such that the natural biases that I hold were thoroughly understood. Through this process of remaining self-reflexive (Maxwell, 2005; Tracy, 2010), it is more likely that the results display the participants' stories rather than my pre-conceived idea of what the result should look like. In addition to remaining self-reflexive, peer review (Creswell \& Miller, 2000) was utilized during the creation of the data collection instrument, during the 
construction of the results, as well as even during the formation of the research question itself.

\section{Participants}

Overall, five participants either responded to the message disseminated by the gatekeeper or reached out as a process of snowball sampling. Four of these participants were athletes from a women's NCAA team. One of the athletes was a new player who had not yet officially played a game for Coach Tom, one of the athletes was a current player for the team, and two of the athletes played their final season in the year after Coach Tom's passing. The other participant was a long-time assistant coach for Coach Tom. All of the interviews took place approximately two years after the death of Coach Tom.

\section{Coach Tom}

Coach Tom established a women's NCAA team and over the course of his respected career, he built the program into one that would rival older, perennially nationally ranked teams. Coach Tom was diagnosed with cancer twice during his tenure with the team. After successful treatment, he was medically declared to be in remission from his first cancer diagnosis. Unfortunately, the cancer relapsed only a few years after his remission diagnosis. Just months after receiving his second cancer diagnosis, Coach Tom passed away. The following results chronologically document the emergent themes that were drawn from the interviews with the participants. 


\section{Results}

The following themes are organized into four chronological categories that serve the purpose of presenting the results contextually within the team's experience of bereavement. However, it is important to note that these chronological sections are not themes in and of themselves; they are organizational tools. In the first category of announcing the relapse, the team's pre-bereavement experience is discussed. This category documents the experience between the time the team was told of Coach Tom's health crisis to the moment just before his passing. In the second category of the coach passes away, the themes of being denied attendance to the funeral and varied experiences of grief and coping are discussed as the team learns of Coach Tom's death while simultaneously preparing for the upcoming season. In the third category of the season, the themes of memorials, tributes, and the continued presence of Coach Tom are discussed while the team describes competing in its first season without Coach Tom. Finally, the category of continuing the culture briefly discusses how the team has perpetuated the memory of Coach Tom in the seasons that have passed.

\section{Announcing the Relapse}

The first event that the participants discussed was the announcement of Coach Tom's relapse. Coach Tom made the announcement to the team on the outset of a pre-season practice. Each of the participants reported a different emotional reaction to hearing the news; some were "shocked," and others were "scared." Despite the seriousness of the diagnosis, the participants reported more concern regarding the head coach's insistence 
on attending practices despite being clearly very sick, sometimes becoming physically ill at the practices and then continuing.

Although the players were upset with the diagnosis, the range of concern over the coach's mortality was limited. This was partially due to the coach's previous recovery from cancer and partially due to the strong and at times humorous front that the coach presented to his players. It wasn't until the coach uncharacteristically missed a practice when the reality of the situation began to hit them:

But, I don't think we fully grasped it until when he started to get really sick. He does not miss practice. He never, ever missed practice. And he missed a day. And that when we all realized, oh... shit. He's not doing as well as he is letting us believe he is. (Anna)

As the coach's condition worsened, Coach Tom's absences grew more frequent.

Eventually, the coach was admitted to a hospital to counteract a treatment complication. While in the hospital, he made the decision to not allow any players to come visit him. This decision upset some of the players, but longtime assistant coach and friend explained the rationale behind the head coach's decision:

At that point, at the very end, he was not really conscious, he had a tube and it wouldn't have, I mean it might have been helpful for them. I don't know, but it wasn't like they could talk to him and say goodbye. (Joe)

Indeed, one of the players concurred, as she would have rather preserved the memory

of her coach in the way he was as her coach and not as a hospital patient:

I was completely ok with it. I did not want to see him whatsoever. Everyone that I had talked to like his wife and our assistant they were all like, "He doesn't look good." And to me what I see right now is him yelling at me. And I don't want to see him, I've seen relatives in that state and I don't ever want to imagine him in that kind of physical state or seeing him that way because I don't remember him like that and I don't want to. (Stephanie) 
As the coach's time in the hospital extended, some of the players grew desperate for updates on his condition, updates that were too infrequent for some of the players. Unfortunately, after a multi-week long fight with the treatment complication, the players all received the one update they hoped that they would not. They were informed that their head coach had passed away.

\section{The Coach Passes Away}

In this chronological section, participants discussed their experiences of bereavement between the time of learning of Coach Tom's death to the time they played their first game without him. Two major themes emerged during this point of their experiences: the impact of being unable to attend Coach Tom's funeral and the athletes' various experiences of grief and coping.

The funeral. In western culture, the generally accepted tradition that follows a death is a funeral. The people who have a right to attend the funeral is determined by a variety of factors, but none so much so as the family's preference. In this instance, the head coach's family had a long standing tradition of holding small, extremely private funerals after a family member had passed away. In continuing with this tradition, only family members of the coach were invited to the funeral. The assistant coach was not critical of the decision because of his respect for the family, but he politely voiced his disagreement with the decision because he was hoping a formal service could have provided for all the people the head coach had made a positive impact on an opportunity to celebrate his life:

I was like wow, because it's the kind of thing thousands of people would have shown up at. And it was hard because people didn't get to grieve the way [they] wanted ... what I expected of Tom's you know, that there would be all these people telling stories and that we could all walk away feeling good about you 
know, the impact he had on all of us. And we didn't get to do that so that was...it was hard. I wish we would have had the chance. (Joe)

The players were likewise uncritical of the family's decision to hold a private funeral which they could not attend. In general, the players communicated a sense of reserved disappointment in not being able to go. The players vocalized the utmost respect for the family's decision as each player quickly followed with a steadfast rationale that defended the family's decision. A player defended the head coach's spouse's decision:

Not that our relationship was less important... But his family was more important and obviously his wife knew him better than anyone else. And it was her right to decide who was going to go to the funeral. And it was her right to let their family go and let the family grieve. (Anna)

Despite the steadfast defense of the family's decision to hold a private funeral, it was evident during the interviews that being unable to attend the funeral had an emotional effect on the participants as several participants became emotional during this portion of the interview. However, it is not possible to determine whether being unable to attend the funeral had any lasting psychological effect on the athletes or if it had an effect on the process of coping.

Varied experiences of grief and coping. In the time immediately following the death of the head coach, the participants generally reported common emotional signs of grief, the most common of which was crying. Some of the players reported crying through some portion of their practices as they would have flashbacks and remember the previous head coach once providing feedback in a similar circumstance. The assistant coach suggested during the interview that the crying was sporadic and not at all interruptive of 
practice; but when those occurrences happened he often found himself having to provide comfort to the players spontaneously:

...like some of them cried. Some of them you know just all of the sudden... I would be going to practice or something and a girl would come up and she would just give me a hug and start crying. That happened more than once... (Joe).

The other most commonly referenced grief-driven emotion felt was that of having a sense of "surrealness." This feeling was not limited to the moments just after Coach Tom's death, one player even reported continuing to have this feeling well after that season ended and into the following season:

You know, it's kinda crazy I think all of us every day...we're like just waiting for him to walk on the field. You know, it was still so surreal; to this day I still feel like he's going to walk on the field. At any day. And it's just so crazy to me, like I feel like he just took time off. You know? It just still hasn't like sunk in completely. (Stephanie)

Participants were asked during the interview to explain whether or not they felt they were being judged for grieving over the loss of their coach. This question was designed in an effort to examine whether or not there were any negative experiences of bereavement that were generated by the participant's dominant social system. Indeed, two players indicated that they felt like they had been. Although both experiences were similar in that they felt they were being judged, the social dynamics that drove them to have that feeling were completely different. One player shared her experience of being judged by her roommate:

... from one of my roommates actually. It hurt actually a lot. She was on another team and she had said like, "Oh the only reason why like, you guys like..." I don't know if she said hated but, "You guys complained about Tom all the time when he was alive and now he's dead like you guys are treating it like he was the best thing ever." That really hurt for her to just kind of say that out of the blue. (Linda) 
Another player shared her experience of being judged because of her status as a player who did not have enough experience playing for the head coach to have developed an attachment worthy of grief:

Some of the upperclassmen early on said that they felt...especially the freshmen... had no right to grieve. That we didn't know him well enough. It didn't last very long, but at the very beginning with everybody else, with everybody's emotions running rampant, a couple of the upperclassmen did make known that we had no right to grieve the way they were. (Ava)

Ava later stated that she understood why the upperclassmen would feel that way, but she also stated that she did not appreciate how that message was delivered.

Participants mentioned a variety of actions that facilitated their coping process during this period. For example, they unanimously spoke of times of sharing memories collectively, especially in a humorous way. Some players talked with each other frequently during this process to help collectively process their feelings. Others coped with their grief by working harder in the gym. The assistant coach mentioned the how participating in their sport was a method by which the players and he were able to cope with their collective grief:

It was a relief that we were just playing instead of thinking about him. So, that's maybe odd but, it sucked always thinking about it and at the top of your mind when you first get there. But once you start playing, it's just the game. So, to me it was a relief, and it was a relief to be around the team and to be, you know there's a lot of camaraderie on the team. And, a lot of people working for the same goal and all that, to have that, to be like doing something I guess you know, instead of just be mourning? We had something that we needed to do and work on that was a healthy, nice distraction... Maybe it's a bad analogy but it's like when you lose... If you have a game, a really bad game and you lose, the first thing you want to do is you wanna play because then you don't have to think about that bad game. But when you have a bad game and you're just sitting around, it's miserable when you're waiting to play. It was like that. (Joe) 
In addition to coping with the death as individuals and as a team, the team was also offered an abundance of outside support. This external support came from friends, family, roommates, staff, faculty, the team's athletic administration, the university counseling center, local area sporting teams, university teams from across the country, and players' extracurricular organization. Although the overwhelming support was unanimously appreciated, one player reported how the consistency of the support was starting to wear on the team:

But there were times when we're just like, "Please, just leave us alone." It got to be almost to the point where we're like, "We know we can get help. Just please, let it go." You know? It was just so annoying. Every day having people come in and like remind us, over and over again that we lost our coach. Like, we know. Like if we need a counselor you came on Monday, you don't need to come on Wednesday we have your business card, we'll call you if we need you. Just leave us alone. You know? It got to be very overbearing after a while that we were just tired of thinking about it and hearing about it. (Stephanie)

Stephanie brings up an intriguing prospect that in some instances too much social support may become a source of stress in and of itself. Managing the entire community response would be an impossible task to coordinate; however, managing a single source of social support may simply be a matter of business practice. Community response staff, such as the counselors in Stephanie's quote, should be aware of the fact that their continual physical presence may not always be welcome or beneficial to those who they are trying to help.

\section{The Season}

Here the athletes discussed their experiences of bereavement during the course of the first season playing without Coach Tom. Major emergent themes included the 
development and wide application of memorials and tributes as well as the team's perception of Coach Tom's continued presence with the team during the season.

Memorials and tributes. The difference between memorial and tributes is not explicitly defined in the research and is subject to a fair amount of vernacular ambiguity. In this paper, a memorial will be defined as any gathering of people which has the intent of remembering or honoring the deceased individual. A tribute, on the other hand, will be defined as any action or object which plays a symbolic role in remembering or honoring the deceased individual.

The number of memorials and tributes that honored the head coach was quite notable. The extent of these events may have been a coping response to help balance the closure they were not able to receive as a result of not being able to attend the actual funeral. Chronologically, the first memorial the players and coach mentioned was a dinner held by the team in the weeks following the coach's death with the explicit purpose of remembering the coach. However, the most salient memorial to all of the participants when discussing memorials, was the impromptu gathering held on a beach just hours before the team's first game of the season. The new head coach took the team there in an attempt to help provide the team a space where they could collectively grieve, away from the field of play, foreseeing the emotional difficulties that lied ahead. Participants reported that the air of that memorial was light and fun, telling fun stories of the coach and writing his name in the sand.

In terms of tributes, there were none so readily apparent as the creation and application of the word "TomStrong." The word "TomStrong" was displayed in several 
different places including: rubber wristbands, team jackets, social media, and a banner.

The word eventually even became the subject of the team's pre-game cheer. For all intents and purposes, "TomStrong" described the spirit of the organization in the season that followed the coach's passing.

The considerable application of "TomStrong" was discovered during the process of investigating the population during the initial design of the study and its importance made explicitly apparent during the course of the pilot interview. Some participants defined

"TomStrong" in terms of the head coach's characteristics or in other words, what being "TomStrong" is:

[Tom] was probably like the strongest person I have ever and will ever meet. And like I mentioned when I said that he told us that he had cancer and like was super positive about it. Like, that positivity defines who he was. Like, obviously he'd yell at us sometimes, but I mean what coach doesn't? So, but even with that if you'd go and talk to him afterwards, he would talk it through with you and be positive with you about it. And, and not even about sport stuff, you could talk to him about anything and he would help you find a solution, help you learn how to tackle it. He was a person you could rely on to be strong for you when you couldn't. As cheesy as that may sound. He always has something good to say and he always had a good story to tell you to cheer you up. (Anna)

Others defined "TomStrong" not only in terms of what being "TomStrong" is, but how to embody being "TomStrong" as an athlete:

So we describe it as someone who is willing to fight no matter what. Because he fought cancer the first time, he fought it the best he could the second time. But in the end, the only thing we were ever told is that he never gave up. So, we actually had a cheer. That was, "What are we? Strong! How strong? Very strong! How strong? TomStrong." And essentially we just meant that like we're gonna fight and we're going to go 'til the end. And I think that that's a big part of us going to the tournament because in order for us to get there we do have to fight because we're in the highest conference. And it is extremely difficult for us to get there so, it's just that continuously fighting and never giving up and always giving everything you have regardless of what happens. And, at the end of the day like knowing that you gave everything you could in the game and not even thinking 
about looking back on it because you know you couldn't have done anything different. (Stephanie)

There were several instances where participants speculated on the effect that the head coach's death may have had upon the alumni. The assistant coach spoke about the difficulties the alumni players may have had in their own personal bereavement process because they were disconnected from the community.

And that was, I think really hard for the former players that didn't have that they didn't have the memorial and then they also didn't have getting to go and play the way we did. (Joe)

Perhaps, as part of their attempt to grieve and cope publicly as well as honor the memory of their former head coach, a group of alumni players created a tribute of their own in the form of a large banner that said "We are TomStrong." The banner was unveiled right before one of the games during the season. Although it was a great gesture by the former players to unveil this tribute just before the game, the timing of the unveiling perhaps was not ideal:

We didn't want their mind on Tom when we were playing. I mean I think, an example of that I told you one of the former players made a big banner and we were down at a big tournament, and they brought that to the tournament for some players that have seen it and kind of unfurled it right before a game started. Played really poorly. We lost the game and that might have been, it was like all of us got hit in stomach you know? Because it was emotional to see that and it kinda impacted them you know. Negatively maybe's the wrong word but, in terms of playing well it impacted them negatively. In terms, you know, they all thought it was a great honor and then they hung that thing wherever we went and they all appreciated it but it was a hard thing to see. (Joe)

Much like the stress caused by the repeated appearances of the counselors, this banner was another example of well-meaning social support being delivered imperfectly. Gestures such as these come with the best intentions and in this instance the alumni 
players were likely also experiencing their own bereavement. However, if the performance of athletes is critical, such as in NCAA collegiate athletes, then these gestures should be made with respect to how the athletes may react to them. Timing may be a significant factor here and it perhaps would not be unwise to coordinate the display of similar gestures with the team itself.

Continued presence. Players and the coach discussed the impact of remembering and sharing memories of their head coach as they proceeded through the season. This would hold especially true as the team would revisit sites or even visit new places that the previous head coach would have had the team go during travel. Assistant coach Joe spoke of how memories of the coach in certain locations helped perpetuate his presence during the season:

...there's probably a lot of more positive, remember Tom would do this or Tom would do that or what would Tom say about this? We would go and eat at restaurants that he would have taken us to when we'd be on trips and he was always, his presence was still there... (Joe)

In addition to propagating the memory of their deceased coach, as well as using the memory of his strength to motivate their play, the players began to attach the coach's name to everyday occurrences in what seemed to be an active attempt to continue to create new memories with him. One player shared a great example of this continued presence that the players had built of their former head coach:

...when the sun shines through the clouds, we call it "TomRays". Because after our first like major win of the year, after we played a game and we beat, I don't even remember, but we beat somebody at home but it was a crazy win, we were like there's no way we're going to pull this out. And we ended up winning and the sun shined through the clouds and there were rays and that's why we call them TomRays. And when we just beat another team, it did it again. We just joke where the wind would blow at games when there'd be like bad calls or something, 
we'd say it's Tom being pissed. There was one game where we had two of our girls get three ejections so they were out of the game and on the third ejection this big ol' thing of wind picked up and all the programs went all over the place. And we were like, "You guys, we gotta pick it up guys, he's getting pissed." So, that's our joke about it, it's just that he's at all the games. (Stephanie)

A major theme of the study overall was the way in which the athletes utilized the name of Coach Tom. The most obvious example was "TomStrong" but here we see "TomRays" and in another interview the term "a TomTurn" was mentioned. The extensive utilization of Coach Tom's name is a curious phenomenon and the exact reason for this Tom branding is difficult to understand. It is possible that by branding day to day occurrences with Coach Tom's name, the team was actively creating a collective continued bond with its deceased coach.

\section{Continuing the Culture}

Following the immediate season after Coach Tom's passing, the team has committed themselves to perpetuating the memory and culture that was instilled during the head coach's tenure. The majority of this continuity comes in the form of annual tributes and memorials, such as the tournament or the scholarship. An unexpected means of culture continuity was unveiled during the interviews as it appears that certain members had turned to inculcation of the newest members of the teams. Players who joined the roster after the coach's death who had never met or experienced the head coach were quickly introduced to what the coach represented and how the team will try to carry on that memory.

And so right from the get go, we're like, we're saying something about Tom. It needs to be said, it's going to be said. And the new head coach actually brought up Tom, and talked about what TomStrong is and how badly he wanted to go to NC2As [NCAA Tournament]. And we talked, and we got pretty emotional talking 
about him to the freshman because it's like, we're talking to people who have no idea who this guy is. Because if they haven't come to games, they don't even know what he looks like, you know and it's kinda crazy to think that people don't know who Tom is. But, we talked to them and we're like, "You guys don't understand like, the drive that this guy had. And the drive that he had to do something for this team." And in order for us to make NC2As we need to stay together and we'd say some of the things that need to happen to go to NC2As and it just, we tried to push it along but you can tell like some of them, you know, don't really understand it. Which is totally understandable, they didn't know who he was, they, they never talked to him. (Stephanie)

Even so, the players have since realized that it is one thing to continue the culture of the organization to honor the memory of their head coach, it is something else entirely to pine for the impossible return of the head coach and perpetuate an unfair comparison upon the new head coach. A player explains:

Because it was like constantly comparing Tom to the new head coach and we finally just had to say you know what? We can't do this anymore, it's not fair to us, it's not fair to him. We can't compare because it's not going to change, we are not going to be able to change that. And we just need to be fortunate that we had those years with Tom... (Linda)

Developing continued bonds with the deceased is a normal, but complex process. Bereaved individuals are encouraged to develop these bonds if they feel that it will be beneficial to their coping process. However, these continued bonds must remain healthy and not risk becoming unhealthy longing. It is encouraging to see that the collective grief policing of the team was acting favorably in this instance as a reminder to keep mindful of the new relationship that was developing with its deceased head coach.

\section{Discussion}

Davis and Jowett have found that in many instances, coaches can fit the role of a secure attachment figure (Davis \& Jowett, 2010; Davis \& Jowett, 2014) and by doing so indirectly confirmed Ainsworth's (1989) suggestion that a coach is an example of a 
potential "parent surrogate." With this being the case, it could be inferred that experiencing the death of one's head coach could be similar to losing other typical secure attachment figures (e.g. a parent) which means that there might be potential for a very adverse emotional response to losing one's head coach. It was not possible to numerically gauge how "attached" these players were to their coach but, from the words used by the participants to describe the head coach (fatherly, close, supportive, and grandpa) it may be cautiously inferred that the players had viewed Coach Tom as a "parent surrogate." Interestingly, the assistant coach himself pointed out that the relationship may play an important role in mediating the experience of coping with grief from athlete to athlete:

I think if you did this same study with other teams going through the same experience, it would, the results or the things you would hear would be very different based upon what the coach-player relationship was. (Joe)

Although this study was thematically analyzed, the application of theory can help inform with the understanding of the results. This study was primarily concerned with investigating the experience of coping with grief after experiencing the death of a head coach. This analysis was carried out keeping in mind the differences in coping as an individual and actions taken to benefit the process of coping of the entire collective.

By utilizing Jakoby's (2012) cognitive-structural model of grief, we can see the various ways that the social structure of these athletes regulated their experiences of bereavement. In the model, there are five variables which interact with the social structure and, in turn, impact the experience of bereavement. They are: framing rules, which are society's rules for how one should interpret the loss; feeling rules and display rules, which are society's rules which determine how one should feel and display these 
feelings publically; personal resources, which describes the bereaved person's selfesteem; and social resources, which describes resources such as social support. These five variables all influence the experience of grief for better or for worse.

Judging from the large outpouring of social support from the community, it may be interpreted that the players' dominant social structure felt that the way in which the team reacted to the loss, as well as the way the team publically displayed its grief was within the realm of acceptable framing, feeling, and display rules. According to Jakoby's (2012) model, the existence of such a large amount of social support also positively interacts with the team's experience of bereavement by way of being a large and meaningful social resource. However, other scholars have been less certain to claim that social support is necessarily helpful in the process of coping (Strobe, Zech, Strobe, Abakoumkin, 2005).

There were only two instances in which members of certain players' social structures negatively moderated the players' experience of bereavement. In one instance, a player was told by her roommate that the player's display of grief was not congruent with what the roommate had previously interpreted the player's relationship with Coach Tom. In this instance, the player's feelings and display of emotion was deemed not socially acceptable. This social evaluation may have hampered the coping process of the player. In the other instance, the player described how at the outset of the bereavement experience, underclassmen players were told that they didn't have the right to grieve in the way that upperclassmen players were. It was not clear if this expression was preemptive of any outward expression of grief of the underclassmen players, so it is difficult to say if this was a response to unacceptable feeling and displays. However, this 
certainly is an example of a social structure telling a bereaved person that he or she may not interpret the death in a particular way, thereby being in violation of framing rules. In both instances, this type of social grief policing may be considered disenfranchised grief (Doka, 2002). Although these were only two instances, the results suggest that mental health and sport psychology professionals should be aware of the complexities involved with socially mediated coping.

It is difficult to analyze the coping experiences of a collective since these are complex, personal experiences. Furthermore, some would suggest that collectives do not grieve; instead, individuals grieve within a variety of contexts (Gilbert, 1996). One of these contexts may be a team. However, it is difficult to deny that actions democratically enacted by a team suggests some level of collective coping dynamics. For this reason, individual experiences of coping with grief and collective experiences of coping with grief have been differentiated.

There were a few key experiences that may have played into the team's collective grieving and coping experience. Although the players were reserved in their criticism of the family's decision to hold a small private funeral, it is evident that it had both an individual and collective impact. However, the exact impact is unclear. Ideally, friends would be allowed to attend the funeral (Bowen, 2004). But, the effect of attending a funeral on the process of bereavement may actually be limited; at the very worst, being unable to attend a funeral may facilitate the creation of disenfranchised grief ( $\mathrm{O}^{\prime}$ Rourke, Spitzberg, Hannawa, 2011). One important function of the funeral is that it assists an individual in being socially recognized as someone who is grieving (Romanoff \& 
Terenzio, 1998). With respect to collective grief, Zinner goes one step further stating that attending the funeral is a "right" of a survivor group (Zinner, 1985) and that such actions are necessary to facilitate positive coping with grief of the entire group.

Zinner lists several rights that must be respected as well as several obligations that followed in order to facilitate the healthy coping of the collective (Zinner, 1985). The rights of the team are to: "be acknowledged and recognized as a survivor, as having suffered a significant loss; be informed of facts concerning the death and subsequent actions taken; and be allowed to participate in traditional or in creative leave-taking ceremonies" (p. 53). The obligations of the team are to: "acknowledge publicly the group's survivorship status; make a tangible response to defined immediate survivors on behalf of the group; and make a tangible response within the group to benefit group members" (p. 53). By referencing this model of group survivorship while analyzing the transcripts, we can see that this collective was granted two of its three rights and completed two of its three obligations. Both the missed right and the missed obligation were related to the team's inability to attend the funeral. This may explain why the team developed such robust memorials and tributes to honor the head coach. The decision to keep a funeral private is absolutely the right of a family. However, mental health and sport psychology professionals should be aware of the potential negative outcomes that may be associated with being unable to attend a ceremony that provides closure and an opportunity for collective grieving. 


\section{Limitations and Future Research Directions}

There are several ways in which scholars can continue to build upon this work. First, sport psychology researchers should continue to investigate these tragic events to produce a wider breadth of experience with a varied population. There is a documented difference in public displays of grief between genders (Strobe, 1998) as well as between cultures (Palgi \& Abramovitch, 1984, Strobe \& Schut, 1998). These two variables alone may result in drastically different experiences of bereavement from the same experience of loss. It is imperative to continue analysis across genders and across cultures in order to cover the widest possible range of experience. In this study, the participants were all Caucasian and the players were all female. The assistant coach himself questioned during the interview if the outward expressions of grief would have been the same had his players been male. In a similar vein, it would be also fair to question if the bereavement experience would be similar from sport to sport.

Regretfully, one question not explicitly asked nor probed during the course of the interviews was the perceived psychological effect these memorials and tributes had on the players. With so many being developed and displayed as well as similar patterns seen in previous research (e.g. Vernacchia et al., 1997), these memorials must serve a psychological purpose. The assistant coach briefly mentioned that these had "a huge effect" but did not describe to what end. The assistant coach also went on to say that "it was hard" to see these memorials displayed. The application of memorials and tributes seemingly has performance implications due to their potential to over-emotionalize the atmosphere (Vernacchia et al., 1997). Therefore, future studies should place greater 
emphasis on questioning their role and balancing out their perceived ability to facilitate coping with potential acute decrements in performance.

Also, it was not within the scope of this study to adequately analyze the process of leadership transition from the deceased coach to the new head coach. However, by drawing from the responses of the participants during the course of the interviews it is evident that the transition was difficult for a variety of reasons. Again, the assistant coach on the team was able to provide some quality insight as to why this may have been the case:

I think it's hard. Every coach is going to have their own culture and their own team. And they want to honor the past but they also want to have their, you know, their own culture so how he puts those two together I'm not sure... (Joe)

In that line of thought, future research may want to investigate best practices for coaching transitions during this rare circumstance. The research available on postmortem leadership transitions is limited, but Vernon's (1970) work describing deathdisrupted social systems may prove helpful in analyzing this part of the experience. In this publication he outlines multiple variables in which leadership succession may or may not be successful as determined by the members of the social system.

\section{Practical Applications}

Although the likelihood of encountering a situation where a coach dies during his or her tenure is unlikely, the resulting psychological impact on the team may be such an emotionally unsettling experience that sport psychology professionals should have quality resources to consult for designing service provision. The preceding study may not have been an applied case study, however, studies like this one catalog valuable 
experiences with which practitioners can use to inform their clinical strategy when approaching similar situations. The research that exists that documents the psychosocial effect of death in sport is centered mainly around the effect of a teammate. Limited research exists which discusses the effect of the death of other members of the sporting community such as that of a head coach. There are other relationships which should also be investigated such as the effect of: the death of a family member during the season; the death of a referee; and the death of fans during a game. Further research is necessary to document how athletes react differently to death in differing circumstances as well as how to design the ideal strategy to work with these athletes.

Additionally, applied sport psychology professionals can utilize the results of this study to increase their awareness of the range of potential psychosocial outcomes that may be encountered during the process of service provision. The preceding study unveiled a series of psychosocial outcomes which will require additional investigation to determine ideal service provision such as: the psychosocial consequences of intra-team grief permissibility by class status; the appropriateness of public tributes and their timing with regard to athlete performance; performance consultation under times of strained leadership transition; and the appropriate development and application of effective memorials which honor the deceased.

The preceding results suggest that coping with the death of a coach is a complex psychosocial process with both intra- and interpersonal variables that must be carefully navigated. Therefore, it is imperative that applied sport psychology professionals and mental health professionals draw from experiences such as these as well as consult works 
which have described comprehensive strategies (e.g. Anderson, 2010; Buchko, 2005; Vernacchia et al., 1997) of service provision should they encounter similar circumstances. 


\section{CHAPTER 3: EXTENDED REVIEW OF LITERATURE}

Although the death of an athlete is not a common occurrence, it warrants academic analysis and inspection because of the potential for an adverse emotional impact on others. There are studies which document how athletes handle death; however, those that have been published are limited and that which does exist focuses almost entirely on the experience of losing a teammate. This study is focused on documenting the experience of a team whose head coach passes away during his tenure. This review of literature will take an interdisciplinary approach to help gain insight into this uncommon phenomenon. Academic works will be drawn from the fields of psychology, sociology, and education in order to elucidate both traditional and current models of grief and coping among different populations. Previously published studies and case studies will be inspected to help illustrate the outcome of similar situations. The purpose of this study was to qualitatively analyze the bereavement experience of a team after the death of its head coach during his tenure.

\section{Traditional Approaches to Coping with Loss}

The experiences of grieving a death and coping with the loss have been well studied since Sigmund Freud made the first major contribution to the field of grief when he published his work Mourning and Melancholia (1917). Contrary to the perspective of current researchers, Freud viewed grief as an illness, one that took a dedicated effort or "grief work" to progress through in order to return to one's baseline of healthy living.

Freud supported a separation strategy towards the deceased, meaning that he recommended to his clients that they should break the emotional bonds that they once 
held with the deceased in order to cope. This approach to grief and coping is no longer as widely supported; instead it is considered to be healthy to form a continued bond with the deceased (Root \& Exline, 2014).

The most well-known theory of grief comes from the work of Elisabeth Kübler-Ross. Her seminal book titled On Death and Dying (1969), was a collection of her observations from working with cancer patients receiving palliative care and the families that supported them. Her primary occupational responsibility in that field was to facilitate the patient's acceptance of certain death. Drawing from her repeated experiences with these patients, she distinguished a repetitive pattern of coping which became known as the five stages of grief. These stages were labeled: denial, anger, bargaining, depression, and acceptance. Kübler-Ross found that it was a common occurrence for patients to follow this path on the way to coping with their grief. Interestingly enough, Kübler-Ross found that these five stages applied not only to the dying patients, but to the bereaved survivors of these patients as well. The common factor between the two parties was the experience of loss. The patient was losing his or her life, and the survivors were losing the patient.

Although Kübler-Ross' original work was extremely important to the development of grief studies and is still widely used today, it has faced criticism recently for multiple reasons. The most commonly criticized aspect of the model is its implied linearity (Marcu, 2007). As read, Kübler-Ross' stages of grief model implies that one progresses through these stages one after the next when in actuality this may not be the case. People may experience multiple stages at once, skip a stage, and possibly even regress 
backwards a stage (Raphael, 1994). Kübler-Ross later contended that the implication of implied linearity was never the model's intention:

The stages have evolved since their introduction, and they have been very misunderstood over the past three decades. They were never meant to help tuck messy emotions into neat packages. They are responses to loss that many people have, but there is not a typical response to loss, as there is no typical loss. Our grief is as individual as our lives (Kübler-Ross \& Kessler, 2005, p. 7).

Despite this clarification, there have been continued critiques. Some examples of these criticisms include, “... lack of trans-cultural validity, omission of the social aspects of adjustment, and stages and tasks being prescriptive for experiencing dying or loss" (Marcu, 2007, p. 398).

Prescriptive models, such as the one proposed by Kübler-Ross (1969), are being replaced by models that are more dynamic with respect to the process of grieving and, more importantly, more readily include the social influences of bereavement. This aspect of the grieving process is pivotal in the coping experience of college students especially (Balk, Tyson-Rawson, \& Colletti-Wetzel, 1993; Battle, Greer, Ortiz-Hernandez, \& Todd, 2013). The university atmosphere is not an ideal setting to facilitate healthy coping. Battle et al. (2013) listed three potential reasons why this is the case. First, college students are in the process of developing an independent identity whilst maintaining a close bond with those who raised them. Typically, college students are removed from their primary caretakers while at the university. In the event of a death of close family member or friend, this separation can make the coping process more difficult because the primary attachment figures on which the student relied for emotional support are no longer within close enough proximity to be utilized effectively. Second, the general 
atmosphere of a university is not supportive of a person in grief. In addition to being academic institutions, universities are also major sites of diversion and there may be a "party atmosphere" inherent on college campuses (Battle et al., 2013). The griever may not want to interrupt either of these activities in order to receive the necessary social support from peers. In the event that the griever has a supportive friend, it is likely that the friend has not yet experienced the death of a loved one and could only offer limited emotional support (Balk et al., 1993). Finally, universities are settings dedicated to achievement. While attending the university, a college student is under considerable pressure from professors, staff, family, and peers to perform well academically. The process of bereavement is not conducive to continuing to perform well and the bereaved student may feel pressured to continue excelling despite facing considerable emotional trauma. For a college athlete, the pressure is multiplied due to the fact that he or she not only must perform well in school; but he or she also faces enormous pressure to perform on the field of play. For an athlete on scholarship, the pressure may be considerably higher.

One commonly cited model that has been offered as an alternative to Kübler-Ross' (1969) stages of grief is the dual process model of coping with bereavement (Strobe \& Schut, 1999). Their model differs from previous models in that it does not include stages or phases of grief. Instead, it includes two distinct coping types and is designed as a dynamic system that works back and forth between these two coping types, called oscillation. 
Strobe and Schut's (1999) dual process model describes two distinct types of coping processes, loss-oriented coping and restoration-oriented coping. Loss-oriented coping refers to what we commonly consider to be active grieving. This could include thinking about the deceased person, reliving the past life that the griever and the deceased once shared, thinking about how the deceased person would act in specific situations, or even possibly reliving certain aspects of the death itself. Restoration-oriented coping refers to the work necessary to overcome the supplementary losses that come along with the death. As an example, Strobe and Schut (1999) mention that a bereaved spouse may now have to learn how to complete household tasks that the deceased partner once completed. Nestled under restoration-coping is the reality that one's identity may change as a byproduct of experiencing the death. To illustrate this instance, Strobe and Schut return to the example of a bereaved spouse of who must transition from the identity of spouse to that of widow or widower.

Arguably, the most important concept of Strobe and Schut's (1999) dual process model is the process of oscillation between the two coping types. Strobe and Schut's main contention with this concept is to provide an alternative to previous grieving and coping models which tend to be linear. In other words, previous models such as KüblerRoss' (1969) suggest that the griever will work non-stop through his or her coping process one step at a time. Strobe and Schut contend that after the loss of a loved one the process of grieving is not linear, and whether or not one wants to engage with grief experiences is regulated by the person. At some points in time, the bereaved subject will find themselves compelled to look at old photographs of the deceased and engage in loss- 
oriented coping. At other times the bereaved subject will be more interested in diversions such as watching television in order to engage in restoration-oriented coping. A bereaved person will "oscillate" between these two processes on his or her way to emotional healing. It is this key process in the model that has made it so valuable to the study of grief and coping with loss.

\section{Athletes and Loss}

Astle (1986) lists four possible types of loss that an athlete may face. The first loss is that of a loved one. In this instance, a person close to the athlete has either died or has been permanently separated from relations with the athlete. The second type of loss is that of some personal aspect; Astle notes that the loss of health in the case of an injury or damage to one's self-perception through a game loss would both qualify under this category. The next category is the loss of an item or object. The final loss an athlete may experience is the loss of bodily function as a normal course of the aging process. This paper will be focusing on the first category, specifically the permanent loss of someone through death.

Losing a teammate. Although rare, the potential likelihood of experiencing the death of one's teammate is significant enough to warrant a discussion. There have been several published studies that have chronicled the various experiences teams have faced after a player has died including studies that analyzed: the effect of a player that has committed suicide (Buchko, 2005), the effects on a community after someone died during a risktaking sport (Doka, Schwarz, \& Schwarz, 1990; Kerr, 2007), a player killed by an injury sustained during the game (Karofsky, 1990), and instances of exercise-related sudden 
death that may or may not have been due to a previously unknown medical condition (Andersson, 2010; Henschen \& Heil, 1992; Vernacchia, Reardon, \& Templin, 1997).

The most common cause of death to an athlete covered in the literature is that of exercised-induced sudden death, occasionally caused from a previously unknown medical condition. One of the most publicized deaths of this sort is that of Hank Gathers, a talented college basketball player for Loyola Marymount who tragically passed away on the court on March 4, 1990. In this instance, the autopsy discovered the cause of death to be hypertrophic cardiomyopathy possibly arising from his recently diagnosed irregular heartbeat (Medcalf, 2015).

Case studies. While there are several case studies that analyze the physiological causes of a death in sport, there are only a few that analyze psychological impacts such as how a team collectively coped with the loss of a teammate or member of a sporting community. Presented here are the exploratory works of Henschen and Heil (1992), Vernacchia et al. (1997) and Andersson's (2010) thesis partially informed by KüblerRoss' (1969) stages of grief.

Henschen and Heil's (1992) longitudinal analysis of the effects of an exerciseinduced death on the surviving teammates was the first paper to inductively analyze the team's coping process. Over a four year period, they chronicled the coping experiences of ten college football players after their teammate passed away during a routine weight lifting session. In their analysis, they discovered four prominent themes: disbelief and shock, continued memories, a personal attribute of the deceased that brought up memories, and meanings attached to the event. 
The first theme of disbelief and shock is quite similar to the first phase of grieving as described by Kübler-Ross (1969). These players expressed that they had never experienced one a member of their peer group passing away before. In addition to the typical shock that comes with hearing of a peer member's death, many of these athletes actually witnessed the death event which may have added an extra visceral level to their grieving experience.

In the second theme of continued memories, athletes reported that they would sporadically think about the deceased player. However, players did not report an increased frequency of memories of their teammate in and around football-related activities. Even four years later, players reported that they continued to have memories of the players come into salience at unusual times. At this point players reported that they were beginning to forget specifics about the physical characteristics of their teammate as one athlete said, "I forget his face but still think of him smiling" (p. 221).

The third theme uncovered by the authors was how the deceased player's home state of Hawaii emotionally impacted the surviving players. Many of the athletes interviewed during this longitudinal work expressed difficulty engaging in any activity that included the word Hawaii. Although they expressed no difficulty engaging in the activity of football after his passing, the players reported immense difficulty playing their yearly game against the University of Hawaii. Even at the conclusion of the study, four years after its start, the ten players continued to express difficulty playing in that game. The only exceptions to that finding were the couple players who were only interested in 
travelling to Hawaii games so that they could visit with their deceased teammate's surviving family members.

The final theme that Henschen and Heil (1992) uncovered was that there was a common meaning derived by the players regarding the loss of their teammate. Players expressed sentiments common to traumatic events such as, "I now appreciate what I have" (p. 221) or "I wonder about how frail our existence really is" (p. 222). The authors made certain to note that they could not be certain as to whether or not these responses were something native to football, or if they are simply reflective of a common cultural response to experiencing a death. Ultimately, Henschen and Heil (1992) concluded that the experience of an athlete coping over the loss of his/her teammate was not far removed from the typical response of a non-athlete grieving over a friend or family member.

Vernacchia et al. (1997) chronicled the emotional aftercare of a team who lost one of its players to a heart attack caused by an abnormal heart rhythm. It is important to note, however, that this player did not die on the court or in any sporting environment; he passed away in his sleep. During the critical incident stress debriefing (CISD) emotional counseling sessions that were being administered to the surviving athletes, the authors categorized major grieving and coping stages they encountered as the team progressed through its emotional coping. The team experienced stages of: shock, confusion, and denial; performance resolve; realization of loss; glorification and memorialization; closure and relief; avoidance and debriefing; and reentry and acceptance. These themes were more sport focused than the one's produced by Henschen and Heil (1992). 
Similar to the findings of Henschen and Heil (1992), the initial stage of the Vernacchia and colleagues (1997) study, shock and denial, also was similar to the first stage defined by Kübler-Ross (1969). Also, akin to Henschen and Heil (1992), the authors noted that this death could be more impactful than other deaths the athletes may encounter due to the fact the deceased was a similarly-aged peer. When these athletes lost their teammate, it may have been the first time that any of them had experienced this type of loss.

Their second reported stage, performance resolve, is the first stage that has been discussed which is specific to the world of sport. The players met within hours of their teammate's death and during that meeting had decided to continue to play in spite of the loss. Interestingly, when making the decision the players often referenced their perception that the fallen player would have wanted them to continue without him. Of all the quotes the authors mentioned in the paper, not one athlete mentioned continuing to play for themselves.

The third stage marked the moment the players recognized the loss within the organizational structure of the team which impacted play. They reached this stage during their first practice after the player's death when the coaches and staff had to readjust previously drawn up plays to compensate for the deceased player who would now be missing in the play.

The fourth stage of the team's coping process was glorification and memorialization. This phase of an athlete's grieving seems to be ubiquitous among the athletic community. After this player's death, many athletes of the survivor group were determined to honor 
the player in their own, unique way. Some opted for simple tributes (e.g. inscribing the deceased player's number somewhere on their equipment), some opted for much more permanent shows of dedication (e.g. tattooing the player's name or number onto their bodies.) Although these displays may have seemed innocuous, the authors argued that this wide-spread extent of memorialization may have been too much. The authors noted that the first game's atmosphere was "overemotionalized and overmemorialized" ( $p$. 230). From a strictly performance standpoint, this was not ideal and may have been a contributing factor in the team's loss during its first matchup after the player's death. In addition to the emotionally charged setting, the authors cited that each player's extreme resolve to perform in honor of the deceased player may have been too distracting to be conducive to performing well.

The fifth stage described in the Vernacchia et al. (1997) paper was that of closure and relief. Due to the close proximity of the coming game, the team was unable to hold a memorial to honor the player prior to its next competition. The authors believed that this was not an ideal situation and it may have been better to reschedule the game for a later date if at all possible. Unfortunately, this was a logistical impossibility as their next game was a scheduled tournament match. After the over-memorialized loss, the players expressed their relief at no longer have to worry about performing well as they were selfaware of their current emotional shortcomings.

The sixth stage was that of avoidance and debriefing. Unlike the players interviewed in Henschen and Heil's (1992) study, these players expressed a certain amount of difficulty in returning to any basketball-related activity or location (e.g. the practice 
gym). Players experiencing a continued, adverse emotional reaction were given extended support from the school's counseling service to help them through this stage. It is not possible to tease out the reasons why one team was able to continue playing while the other team was not as readily able to cope from the articles alone, although it would be an interesting topic for future research.

The seventh and final stage observed by Vernacchia et al. (1997) was reentry and acceptance. Over time, players began to more fully heal from the loss. The team met and decisions were made regarding the establishment of a more formal memorial to the fallen player for the upcoming season. The players decided on a patch which would be worn on their jerseys for the duration of the upcoming season. The team was prepared by the school's counselors for the potential relapse of intense emotions when encountering important dates on the calendar (e.g. the first game). The players were again emotionally prepared by the school's counselors when they were about to encounter the anniversary of the deceased player's death.

Andersson's (2010) thesis explored the effect of an elite runner's exercise induced death on the extended running community. The grief experience of the athletes was primarily informed by and organized utilizing Kübler-Ross' (1968) stages of grief model. Additional findings were inductively analyzed and included themes of: individual coping mechanisms, community coping mechanisms, and individual risk in athletics.

Andersson (2010) found in her thesis that the bereavement experiences of the runners paralleled the first and last stages of grief defined by Kübler-Ross (1968) which, in part, was consistent with the findings of Vernecchia et al. (1997), Henschen and Heil (1992), 
as well as Astle's (1986) characterization of athletes and loss. The runners unanimously expressed shock upon hearing the news of the death. In this study, the runners did not explicitly state that they experienced any of the three middle stages of: anger, bargaining, or depression. There were a few instances where the author attempted to draw connections to these missing stages, but ultimately these stages were not prevalent. Despite not going through many of the stages of grief as defined by Kübler-Ross, many of the runners who were interviewed did express that they had to emotionally work to get to the stage of acceptance. Their ability to reach this stage of acceptance was readily facilitated by the knowledge that the deceased runner had a previously diagnosed heart condition that made him more susceptible to this type of event.

In Andersson's thesis (2010) she noted the diversity of individual coping mechanisms that the bereaved runners utilized; a diversity she blames on a lack of an official emotional counseling procedure to deal with a death. The first mechanism listed was that of religion/spirituality. Runners primarily utilized this mechanism as a way to make meaning and sense from a death that occurred so suddenly and unexpectedly. This should come as no surprise as it has been repeatedly found in the sport psychology literature that one of the primary stress/anxiety coping mechanisms of athletes is actively engaging in their religion through prayer (Czech et al., 2004; Vernacchia et al., 2000; Watson \& Nesti, 2005). One could hypothesize that a stressful occurrence outside the general anxiety that comes from competitive sport would also trigger a similar coping mechanism. The next coping mechanism was the social support that was offered by family and close friends. Intriguingly, one provider of social support these runners 
utilized was the deceased runner's widow. The last individual coping mechanism the Andersson found was running. Running was primarily utilized as a way to draw focus away from the loss and towards something proactive. The act of engaging in one's primary sport after the death of a teammate has been contentious in the previous two studies. Whereas the football players in Henschen and Heil's (1992) study has no problem returning to activity, the basketball players from Vernecchia et al. (1997) study had emotional reservations about returning to the court for some time. Andersson's (2010) findings are interesting because they may suggest that return to play could be a coping mechanism provided that the bereaved athlete could actually make it to the field of play.

Along with individual coping mechanisms, Andersson (2010) analyzed patterns of community coping and support. First, the grief-stricken community galvanized support for the newly widowed wife of the deceased runner. The community was so steadfast in its will to support the widow that several of members moved for a period of time in order to be closer to her. The next theme of community grieving was the impact of having opportunities to publically grieve the loss. Memorial services performed shortly after his death and the more permanent memorial of a monument proved to be excellent places to grieve collectively. Finally, the running community spoke about the effect of being able to talk to, or not talk to, a central figure about the process of grieving. Although none of the runners utilized any type of professional therapy, many of them turned to their athletic trainers as confidants. The final theme in Andersson's thesis was related to how 
the athletes were faced with the new idea that running was a risky sport, an idea that many of them rejected even after the deceased runner's death.

Losing a coach. Although there has been no research conducted on the effect of experiencing the death of one's coach, it can be hypothesized that the psychological effect on the athletes would be significant. Davis and Jowett (2010) conducted an exploratory study in which they revealed that coaches meet the criteria to fit the role of a secure attachment figure. Examples of other secure attachment figures are parents and romantic partners. Ainsworth (1989) states that an attachment relationship will develop when an affectional bond has been created, which she defines as:

... a relatively long-enduring tie in which the partner is important as a unique individual and is interchangeable with none other. In an affectional bond, there is a desire to maintain closeness to the partner... Inexplicable separation tends to cause distress, and permanent loss would cause grief (Ainsworth, 1989, p. 711).

The results of Davis and Jowett's study are especially compelling because it provides support to Ainsworth's contention that an athletic coach can serve the role of a "parent surrogate" (Ainsworth, 1989, p. 711). In the same publication, Ainsworth makes a case that "parent surrogates" should be considered by research as well. Therefore, it may be inferred that there is potential for a very strong grief response when experiencing the loss of a head coach.

There may not be any formal research conducted on this phenomenon, but there have been publicized instances of a coach's death in the media. One notable instance is that of Coach Flip Saunders, previous head coach of the Minnesota Timberwolves, who passed away in 2015 after a battle with lymphoma less than a week before the season began. Without formally interviewing the players from that team there is no way to fully 
understand the psychological impact that Coach Saunders' death had on them. However, there was a significant presence of NBA players expressing their condolences on social media. Most notably was the Instagram post of Kevin Garnett who quickly posted a picture of himself dressed in a white hoodie and grey pants, seated with his back turned to the camera in Coach Saunders reserved parking spot. The caption read, "Forever in my heart..." Head coaches from around the NBA also wore pins on their lapels memorializing the loss of Coach Saunders for the entire season.

\section{Grief and the Team}

When a loss strikes a sports team or community of athletes, there are myriad grief reactions occurring simultaneously. The sports team, by proximity alone, is a dominant social structure that will influence the grief response of all the individuals. Also, sports teams and communities of athletes have a tendency to not only grieve as individuals, but as a single collective unit as well (Andersson, 2010; Vernacchia et al., 1997). There are three grieving collectives of importance to consider when analyzing the coping process of a team: the grieving individual on a bereaved team, the bereaved team (composed of grieving individuals), and the grieving leaders of a bereaved team. Because of the complexities involved in inter- vs. intra personal grief, the study will benefit from utilizing different theoretical frameworks to facilitate the analysis of each different collective.

The grieving individual on a bereaved team. The individual players on the team do not grieve without influence from their social surroundings. To the contrary, they experience grief alongside their teammates, their friends, their families, their schools, etc. 
That is not to say that people do not develop their own unique coping strategies; they just happen to do this while being influenced by their social surroundings. When it comes to losing a teammate or a coach, one of the most dominant social structures the individual will call upon for social resources is the team. Although Strobe and Schut's (1999) dual process model began to assess the social aspect of grieving, the social processes in that model are not present enough to effectively account for the consistent presence of a team atmosphere and the social support that emanates from that. In order to organize the individual's coping experience after such a loss within the context of a team, the cognitive-structural model of grief (Jakoby, 2012) could be more useful in explaining this phenomenon because of the overwhelming influence the social structure plays throughout the duration of the individual's entire coping process.

The cognitive-structural model of grief (Jakoby, 2012) is a, psychosocial model which was designed to help explain how one's experience of grief and coping is affected by society. As opposed to traditional theories of grief and coping which have focused exclusively on either psychology or sociological explanations, Jakoby constructed an interdisciplinary model of grief which utilized fundamentals derived from symbolic interactionism, structural functionalism, and behavior theory. These fundamentals were then integrated into a single model which ultimately provides a theoretical roadmap to help describe how the process of coping is influenced by the social structure. In this model there are three steps that determine the coping response of the individual: the actual death event, the framing process, and the analysis of feelings and expressions. It is important to note that after the analysis of the death event, every step of the way to and 
including the final coping response interacts with and is influenced by the social structure thus implying the importance of society on grief responses.

The model begins with the event that starts the grief response, which is experiencing the actual loss of a person. Jakoby (2012) posits that there are three issues to consider within the analysis of the death that act as a mediator of the final response: the mode of death, the commitment of the relationship, and the category of the relationship. The mode of death is in reference to the cause of death as well as the expectation of a death occurring (e.g. the unexpected death of a child will elicit a different bereavement response than the death of a grandparent receiving palliative care). In many instances of bereavement that require therapy, the bereaved individuals have experienced an unlikely death which exacerbated the overall grief response (Parkes \& Prigerson, 2010).

Relationship commitment indicates the perceived connection to whoever has passed away (e.g. there is a difference in the grieving experience between losing a close mother versus losing a mother who you have distanced yourself from). Finally, the relationship category specifies who actually died (e.g. friend, minister, parent). The relationship category is extremely important as this relationship plays a paramount role in the overall production of a grief response (Robson \& Walter, 2012).

One important point to take away from the analysis of death and its three variables is that this is the only major category in Jakoby's (2012) model that is not mediated in some way by the dominant social structure. That is not to say that there aren't social implications housed within this aspect of the model because clearly there are. The relationship category is often created as a result of social interaction as these bonds 
formed between others often are a result of who we spend our time with. What Jakoby is pointing out is that during at the analysis of death phase, the social structure has not yet had the opportunity to directly influence or mediate the coping response of the bereaved individual.

The second piece of Jakoby's (2012) model, framing of the loss, is the first of the model that is mediated by the bereaved persons' dominant social system. There are three variables to consider when one develops his or her frame: the personal frame, the family frame, and society's framing rules. The personal frame is associated with one's own beliefs about matters that concern the nature of life and death. Certainly, a prime example of this would be one's religious affiliation and the beliefs that accompany that. For example, an atheist would likely harbor differing perspectives of death than someone who is devoutly religious and believes in the concept of an afterlife. The second variable considered is the family frame. This is in reference to the product of the entire family's collective meaning making process. The family's collective role in the grieving process is extremely important as a negative correlation between the cohesiveness of the family unit and the overall grief response (Traylor et al., 2003) has been documented. The final variable of consideration is the framing rules and it is here where the cognitive-structural model presents its first variable that has significant interplay between the social system and the coping process.

Framing rules are a set of unspoken, yet understood standards about how a particular instance of death is to be processed by the living. This differs from feeling rules and display rules which will be explained in a later section. Whereas the personal frame and 
family frame are more intimate, semi-personal constructs regarding death; framing rules are drawn from society at large. Utilizing religion as an example again, within a strongly religious community the loss of a child may be framed as "The will of God." However, for an atheistic family within this religious community, then the framing of the loss would clearly differ. Due to the noted dissonance in developed frames, public displays of grief by the atheistic family may be altered.

The third category and final variable before the coping response is feelings and expectations. There are two variables that govern this category, both of which are mediated by the dominant social structure, these are feeling rules and display rules. Feeling rules are social constructions that influence one's overall magnitude of grief within a specific milieu. This is readily intertwined with display rules which are also socially constructed, however these determine the actual act of expressing one's grief. For example, feeling rules in modern, western culture dictate that it is acceptable to grieve openly for the loss of someone close, however it is unacceptable for that grieving process to continue for years. An example of display rules can be seen in the context of funerals. It is socially acceptable to cry at this event; however, social decorum stipulates that one should not express one's grief through laughter.

An intriguing antecedent of feeling rules, which derives from the dominant social structure, is the griever's own perceived place within the various echelons of grievers of whoever has passed away. In other words, the administration of feeling rules can vary from one person to the next based on how close the person was to the deceased (Robson $\&$ Walker, 2012). For example, the feeling rules for the mother of a deceased child vary 
greatly from the feeling rules applied to the dentist of the same deceased child. As Robson and Walker point out, there can be significant social dissonance when the publically displayed grieving of someone either exceeds or falls short of the social expectation based on the relationship, thus exemplifying the power of socially prescribed feeling rules.

Finally, the model concludes with "coping" which is intertwined with the social structure through two of its own variables: social resources and personal resources. The most common example of social resources, especially with regard to coping, is that of social support. Personal resources allude to the grieving person's perceived command over one's own life. Although the model ends with coping it is important to note that there is considerable interplay between the three post-death categories as well as the variables that interact with the dominant social structure. Therefore, a major strength of this model is the built in dynamic nature of explaining the coping and grieving process.

Although the cognitive-structural model's potential for interpreting the grief response within a social context is extremely promising; it has been under-utilized in the field of grief studies and has not yet been utilized to examine a death in sport. Despite this fact, the rationale used to construct the model can still prove to be helpful in understanding the coping response of an individual who is influenced by his/her team.

The bereaved team. Just as the individual is impacted by the death of one of his teammates, the team as a collective body is impacted by the loss of one of its members. The team collectively navigates its way through its own coping process, independent of the individual coping of the players. 
Analyzing the coping response of an entire team is decidedly more complex than that of analyzing an individual's response to a death. The traditionally utilized models of grief do not adequately account for the combined idiosyncrasies of all of the involved members into a single, collective response. However, when analyzing group responses to death, patterns of events have a tendency to emerge. Ellen Zinner (1985) packaged these events into her model of group survivorship where she contends that when a member of a group dies, the remaining group members must be considered a group of survivors who have rights and obligations that need to be met in order to facilitate healthy coping of the collective.

Zinner's (1985) model of group survivorship is broken into two main parts: survivor group rights and survivor group obligations. By following this list of rights and obligations, one could predict how successful the coping process of the surviving members will be. The very first right of a survivor group is, “... to be acknowledged and recognized as a survivor, as having suffered a significant loss" (p. 53). This right proclaims that the survivor group needs to be treated as a collective body that must be shown compassion from the larger society. Condolences need to be expressly directed at the collective body instead of just specific individuals considered closest to the fallen member. The team or survivor group has lost together, will suffer together, will cope together, and ultimately will heal together. The second right of a survivor group is, "...to be informed of facts concerning the death and subsequent actions taken" (p. 53). Groups do not want or need filtered information regarding the death of its member. When information is withheld from the survivor group, it is possible that it may not grieve 
healthily. The coping response of a team may manifest very differently between a team that experiences a teammate dying one night for "undisclosed" reasons as opposed to a teammate dying one night from complications of a head injury sustained during the game. The third and final right of a survivor group is that they, “... be allowed to participate in traditional or in creative leave-taking ceremonies" (p. 53). The remaining players are survivors and as such they deserve the type of closure that only a funeral can bring in our modern society. Murray Bowen, father of the therapeutic process called family therapy, makes sure to be inclusive of friends in his discussion on the importance and function of funerals:

I believe it serves a common function of bringing survivors into intimate contact with the dead and with important friends, and it helps survivors and friends to terminate their relationship with the dead and to move forward with life. I think that the best function of a funeral is served when it brings relatives and friends into the best possible functional contact with the harsh fact of death and with each other at this time of high emotionality (Bowen, 2004, p. 331).

In addition to being included in tradition ceremonies, group survivors also reserve the right to play a role in any alternative ceremonies or memorials as well. In any circumstance they should not be ignored as a less important subgroup of the deceased member's life.

As previously noted, Zinner's (1985) model of group survivorship lists important rights as well as important obligations that the group must complete in order to facilitate healthy coping of the entire group. The first of these obligations is, “...to acknowledge publically the groups survivorship status" (p. 53). In response to their right to be identified as survivors, they members of the group also need to make it known openly that they are survivors. This is commonly seen identified in athletics as the type of 
immediate memorial that is utilized. Examples of this can be the jersey number or nickname of the fallen member placed on the back of one's helmet or tattooed onto one's body as one player did in the Vernachia et al. (1997) study to honor his fallen basketball teammate. The second obligation is, “... to make a tangible response to defined immediate survivors on behalf of the group" (p. 53). As much as the group needs to be recognized as survivors of a tragedy, they also need to recognize that they are not the only mourners of the loss and must address the family of the lost member. Zinner suggests that the most common form of recognition is attendance at the funeral by all or a select few members. The final obligation of the survivor group is to, “... make a tangible response within the group to benefit group members" (p. 53). This is the most formal way to recognize the deceased as a member of the group. Responses may be temporary such as a memorial ceremony, or may be more permanent and lasting such as the monument erected in Andersson's (2010) thesis. Zinner makes a sport specific reference to this specific obligation when she suggests that this type of response would include the renaming of a stadium to reflect the name of a deceased coach. 


\section{CHAPTER 4: CONCLUSION}

The experience of athletes coping with death has been analyzed entirely within the context of losing a fellow athlete (e.g. Vernacchia et al, 1997). While athletes make up a significantly large portion of what makes up a sporting organization, they are not the only members. The preceding study adds to the death in sport literature by examining the bereavement experience of athletes who lived and played through the death of their head coach.

The experience of bereavement is idiosyncratic (Kübler-Ross \& Kessler, 2005) even when the loss is shared between a group (Gilbert, 1996). This makes a group analysis of bereavement extremely complex. This study took the approach of using a social-system driven focused of coping (Jakoby, 2012) and model of group survivorship (Zinner, 1985) to help account for the some of these complexities that may arise from a team sharing a loss. Even so, this study represents a small portion of the possible reactions to a loss on the team and even more so as a representative population of the sporting world. Further inspection is required to help provide a more complete picture of the experience of living through the death of a head coach from a variety of sports, genders, and cultures.

Depending on the relationship (Ainsworth, 1989), living and playing through the death of a head coach may be might share similarities with living and playing through the death of a parent. It is an emotionally taxing experience that mental health and sport psychology professionals need to have resources prepared for in the event that intervention is required. These professionals should call upon exploratory research such as this, utilize service provision case studies (e.g. Buchko, 2005; Vernacchia et al., 1997), 
as well as consult with recommend service provision guidelines (Anderson, 2010) to design a comprehensive service strategy that can greatly assist athletes in what may be one of the most emotional, impactful, and meaningful event of their lives. 


\section{References}

Ainsworth, M. D. S. (1989). Attachments beyond infancy. The American Psychologist, 44(4), 709-716.

Amis, J. (2005). Interviewing for case study research. In D. L. Andrews, D. S. Mason, \& M. L. Silk (Eds.), Qualitative methods in sport studies (pp. 104-138). Oxford, England: Sage Publications.

Anderson, R. (2010). Death of a teammate. In S. J. Hanrahan \& M. B. Andersen (Eds.), Routledge handbook of applied sport psychology: A comprehensive guide for students and practitioners (pp. 365-374). New York: Routledge.

Andersson, L. (2010). Impact of a professional runner's sudden death on his training communities (Master's thesis). Retrieved from SJSU ScholarWorks. Paper 3842.

Astle, S. J. (1986). The experience of loss in athletes. Journal of Sports Medicine and Physical Fitness, 26, 279-284.

Balk, D. E., Tyson-Rawson, K., \& Colletti-Wetzel, J. (1993). Social support as an intervention with bereaved college students. Death Studies, 17, 427-450.

Battle, C. Y., Greer, J. A., Ortiz-Hernandez, S., \& Todd, D. M. (2013). Developing and implementing a bereavement support program for college students. Death Studies, 37, 362-382. doi: 10.1080/07481187.2011.634087

Bereavement. (2015). In G. R. VandenBos (Ed.), APA dictionary of psychology (2nd ed). Washington, DC: American Psychological Association.

Berg, B. L. (2004). Qualitative Research Methods for the Social Sciences. Boston, Massachusetts: Allyn \& Bacon.

Bowen, M. (2004). Family therapy in clinical practice. Lanham, Maryland: Jason Aronson, Inc.

Buchko, K. L. (2005). Team consultation following an athlete's suicide: A crisis intervention model. The Sport Psychologist, 19, 288-302.

Creswell, J. W. (2003). Research design: Qualitative, quantitative, and mixed methods approaches. 2nd ed. Thousand Oaks, California: Sage Publications.

Creswell, J. W. (2007). Qualitative inquiry \& research design. 2nd ed. Thousand Oaks, California: Sage Publications. 
Creswell, J. W. (2016). 30 essential skills for the qualitative researcher. Thousand Oaks, California: Sage Publications.

Creswell, J. W., \& Miller, D. L. (2000). Determining validity in qualitative inquiry. Theory Into Practice, 39(3), 124-130. doi: 10.1207/s15430421 tip3903_2

Czech, D. R., Wrisberg, C., Fisher, L., Thompson, C., \& Hayes, G. (2004). The experience of Christian prayer in sport: An existential phenomenological investigation. Journal of Psychology and Christianity, 2, 1-19.

Davis, L., \& Jowett, S. (2010). An exploratory investigation into the interpersonal dynamics involved between coaches and athletes based on fundamentals principles of attachment theory. Journal of Clinical Sport Psychology, 4, 112-132.

Davis, L., \& Jowett, S. (2014). Coach-athlete attachment and the quality of the coachathlete relationship: Implications for the athlete's well-being. Journal of Sport Science, 32(15), 1454-1464. doi: 10.1080/02640414.2014.898183

Doka, K. (Ed.). (2002). Disenfranchised grief: New directions, challenges, and strategies for practice. Champaign, IL: Research Press.

Doka, K. J., Schwarz, E. E., \& Schwarz, C. (1990). Risky business: Observations on the nature of death in hazardous sports. Omega, 21(3), 215-223.

Folkman, S. (1984). Personal control and stress and coping processes: A theoretical analysis. Journal of Personality and Social Psychology, 46(4), 839-852. doi: 10.1037/0022-3514.46.4.839

Freud, S. (1917). Mourning and Melancholia. The Standard Edition of the Complete Psychological Works of Sigmund Freud, Volume XIV (1914-1916): On the History of the Psycho-Analytic Movement, Papers on Metapsychology and Other Works, 237-258. Retrieved from: https://www.free-ebooks.net/ebook/Mourningand-Melancholia/pdf?dl\&preview

Gilbert, K. R. (1996). We've had the same loss, why don't we have the same grief? Loss differential grief in families. Death Studies, 20, 269-283.

Gratton, C. \& Jones, I. (2004). Research Methods for Sport Studies. Hove, UK: Psychology Press.

Grief. (2015). In G. R. VandenBos (Ed.), APA dictionary of psychology (2nd ed). Washington, DC: American Psychological Association. 
Henschen, K R., \& Heil, J. (1992). A retrospective study of the effect of an athlete's sudden death on teammates. Omega, 25(3), 217-223.

Jakoby, N. R. (2012). Grief as a social emotion: Theoretical perspectives. Death Studies, 36, 679-711. doi: 10.1080/07481187.2011.584013

Karofsky, P. S. (1990). Death of a high school hockey player. The Physician and Sportsmedicine, 18(2), 99-103.

Kerr, J. (2007). Sudden withdrawal from skydiving: A case study informed by reversal theory's concept of protective frames. Journal of Applied Sport Psychology, 19(3), 337-351. doi: 10.1080/10413200701342699

Kübler-Ross, E. (1969). On death and dying. New York: Macmillan.

Kübler-Ross, E., \& Kessler, D. (2005). On grief and grieving. New York: Scribner.

Lazarus, R. S. (1993). Coping theory and research: Past, present, and future. Psychosomatic Medicine, 55(3), 234-247.

Lazarus, R. S., \& Folkman, S. (1984). Stress, appraisal, and coping. New York: Springer.

Lincoln, Y. S., \& Guba, E. G. (1985). Naturalistic Inquiry. Beverly Hills, CA: Sage.

Marcu, O. (2007). Meaning making and coping: Making sense of death. Cognition, Brain, Behavior, 11(2), 397-416.

Maxwell, J. A. (2005). Qualitative research design: An integrative approach. 2nd ed. Thousand Oaks, CA: Sage.

Medcalf, M. (2015). Hank Gathers, 25 years later. ESPN. Retrieved from www.espn.com/mens-college-basketball/story/_id/12408850/remembering-hankgathers-25th-anniversary-death

National Center for Catastrophic Sport Injury Research. (2015). Catastrophic sport injury research: Thirty-second annual report. Chapel Hill, NC: University of North Carolina.

O'Rourke, T., Spitzberg, B. H., Hannawa, A. F. (2011). The good funeral: Toward and understanding of funeral participation and satisfaction. Death Studies, 35, 729-750. doi: $10.1080 / 07481187.2011 .553309$ 
Palgi, P., \& Abromovitch, H. (1984). Death: A cross-cultural perspective. Annual Review of Anthropology, 13, 385-417.

Parkes, C. M. \& Prigerson, H. G. (2010). Bereavement: Studies of grief in adult life. New York, NY: Routledge.

Payne, S. Horn, S., \& Reif, M. (1999). Loss and bereavement. Buckingham, UK Open University Press.

Raphael, B. (1994). The anatomy of bereavement. New York: Rowman \& Littlefield.

Robson, P., \& Walter, T. (2012). Hierarchies of loss: A critique of disenfranchised grief. Omega, 66(2), 97-119. doi: 10.2190/OM.66.2.a

Romanoff, B. D., \& Terrenzio, M. (1998). Rituals and the grieving process. Death Studies, 22, 697- 711. doi: 10.1080/074811898201227

Root, B. L. \& Exline, J. J. (2014). The role of continuing bonds in coping with grief: Overview and future directions. Death Studies, 38, 1-8. doi:

$10.1080 / 07481187.2012 .712608$

Strobe, M. (1998) New directions in bereavement research: Exploration of gender differences. Palliative Medicine, 12, 5-12.

Strobe M., \& Schut, H. (1998). Culture and grief. Bereavement Care, 17, 7-10.

Stroebe, M., \& Schut, H. (1999). The dual process model of coping with bereavement: Rationale and description. Death Studies, 23, 197-224. doi:

$10.1080 / 074811899201046$

Strobe, M., Schut, H., \& Boerner, K. (2017). Cautioning health-care professionals: Bereaved persons are misguided through stages of grief. Omega, 74(4), 455-473. doi: $10.1177 / 0030222817691870$

Strobe, W., Zech, E., Strobe, M. S., Abakoumkin, G. (2005). Does social support help in bereavement? Journal of Social and Clinical Psychology, 24(7), 1030-1050.

Tracy, S. J. (2010). Qualitative quality: "Big-tent" criteria for excellent qualitative research. Qualitative Inquiry, 16(10), 837-851. doi: 10.1177/1077800410383121

Traylor, E. S., Hayslip, B., Kaminski, P. L., \& York, C. (2003). Relationships between grief and family system characteristics: A cross lagged longitudinal analysis. Death Studies, 27, 575-601. doi: 10.1080/07481180302897 
Vernacchia, R. A., Reardon, J. P., Templin, D. P. (1997). Sudden death in sport:

Managing the aftermath. The Sport Psychologist, 11, 223-235.

Vernon, G. M. (1970). Sociology of death: An analysis of death-related behavior. New York: Ronald Press Co.

Watson, N. J., \& Nesti, M. (2005). The role of spirituality in sport psychology consulting: An analysis and integrative review of literature. Journal of Applied Sport Psychology, 17, 228-239. doi: 10.1080/10413200591010102

Wayment, H. A., \& Vierthaler, J. (2002). Attachment styles and bereavement reactions. Journal of Loss and Trauma, 7, 129-149.

Zinner, E. S. (1985). Group survivorship: A model and case study application. New Directions for Student Services, 31, 51-68. 